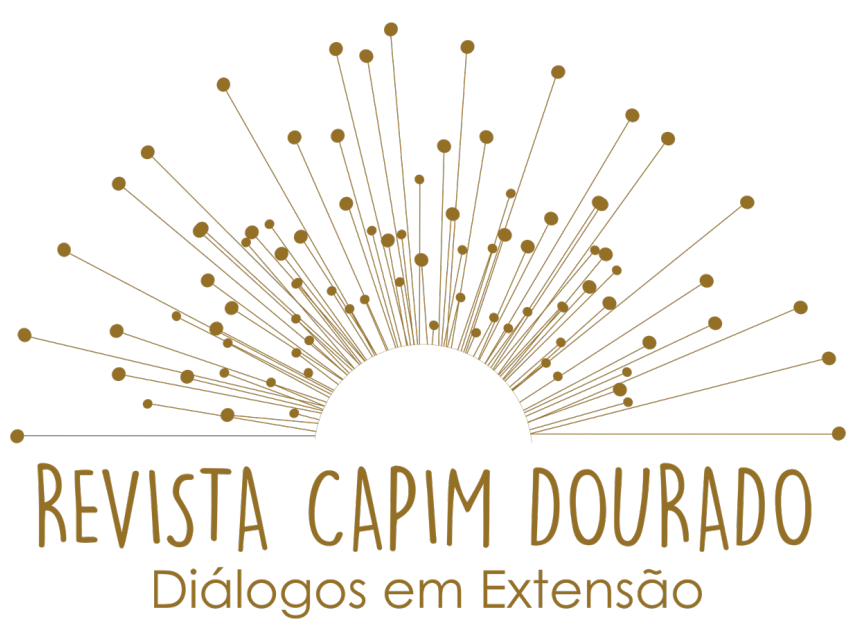

ISSN n² 2595-7341

Vol. 3, n. 1, Janeiro-Abril, 2020

DOI: http://dx.doi.org/10.20873/uft.2595-7341.2020v3n1p222

\title{
A VIOLÊNCIA CULTURAL ESTABELECIDA ENTRE A SOCIEDADE E A COMUNIDADE TRADICIONAL
}

CULTURAL VIOLENCE ESTABLISHED BETWEEN SOCIETY AND THE TRADITIONAL COMMUNITY

VIOLENCIA CULTURAL ESTABLECIDA ENTRE LA SOCIEDAD Y LA COMUNIDAD TRADICIONAL

\section{Alexandre de Castro Campos ${ }^{1}$ \\ Nelson Russo de Moraes ${ }^{2}$ \\ Raquel Cabral ${ }^{3}$}

\section{RESUMO}

As comunidades em geral, e as tradicionais em específico, surgiram no decorrer dos séculos, perdendo seus territórios e sofrendo com a violência cultural imposta pela sociedade, observando a dissolução de suas práticas culturais, traços culturais e crenças em decorrência da fortaleza dos elementos provindos da sociedade, no que the diz respeito de maneira geral traçada no consumo e no individualismo da sociedade que altera a sociabilidade com as comunidades tradicionais que são formadas pela afetividade entre os indivíduos que possuem características próprias na sua organização ocupando e usando os territórios e recursos naturais com condição de desenvolvimento cultural, social e religioso.

\footnotetext{
1 Mestre em Agronegócio e Desenvolvimento pela UNESP / campus Tupã./SP. alexandregeo@hotmail.com.

2 Professor Doutor no curso de Graduação em Administração e Pós Graduação em Agronegócio e Desenvolvimento na UNESP / campus Tupã/SP. nelsonrusso.unesp@gmail.com.

3 Professora Doutora no curso de Graduação de Relações Públicas e Pós Graduação em Comunicação pela UNESP / campus Bauru/SP. raquelc@faac.unesp.br.
} 


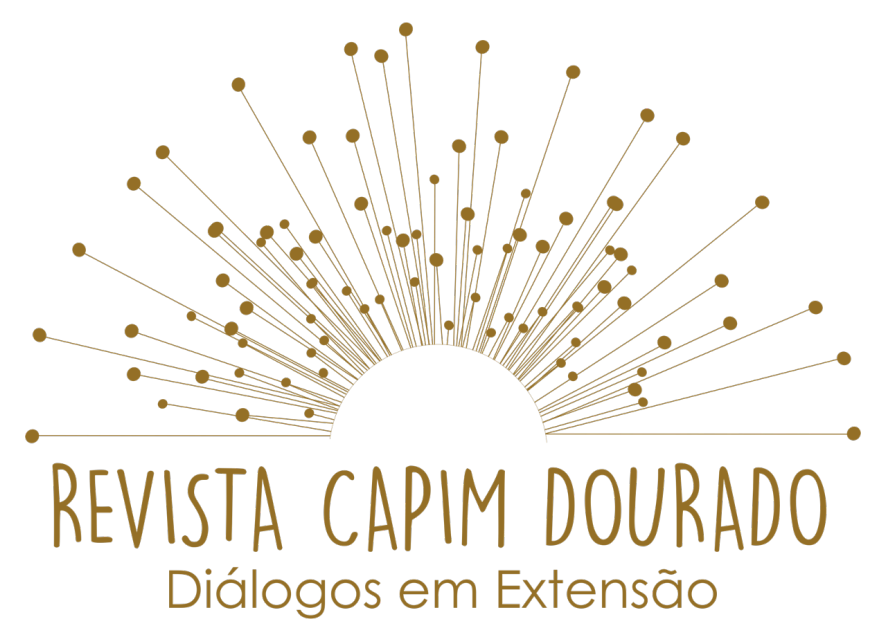

ISSN n² 2595-7341

Vol. 3, n. 1, Janeiro-Abril, 2020

DOI: http://dx.doi.org/10.20873/uft.2595-7341.2020v3n1p222

Dessa forma o trabalho busca abordar de que maneira a violência cultural afeta a sociabilidade entre as comunidades tradicionais e a sociedade através de uma revisão de literatura dos temas sociabilidade, comunidades tradicionais e violência cultural.

PALAVRAS-CHAVE: Sociabilidade. Cultura. Violência cultural.

\section{ABSTRACT}

Communities in general, and traditional ones in particular, have emerged over the centuries, losing their territories and suffering from the cultural violence imposed by society, observing the dissolution of their cultural practices, cultural traits and beliefs due to the strength of the elements coming from society, with respect to it in a general way traced in the consumption and individualism of society that alters sociability with traditional communities that are formed by the affection between individuals who have their own characteristics in their organization occupying and using the territories and natural resources with condition of cultural, social and religious development. Thus, the work seeks to address how cultural violence affects sociability between traditional communities and society through a literature review of sociability, traditional communities and cultural violence.

KEYWORDS: Sociability. Culture. Cultural violence.

\section{RESUMEN}

Las comunidades en general, y las tradicionales en particular, han surgido a lo largo de los siglos, perdiendo sus territorios y sufriendo la violencia cultural impuesta por la sociedad, observando la disolución de sus prácticas culturales, rasgos culturales y creencias debido a la fuerza de los elementos provenientes de sociedad, con respecto a ella de manera general, trazada en el consumo y el individualismo de la sociedad que altera la sociabilidad con las comunidades 


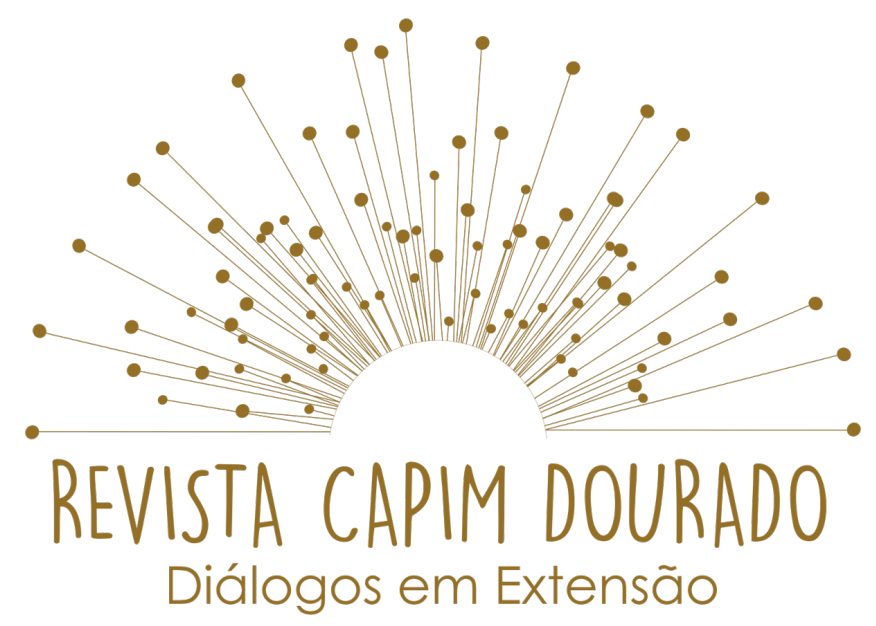

ISSN n² 2595-7341

Vol. 3, n. 1, Janeiro-Abril, 2020

DOI: http://dx.doi.org/10.20873/uft.2595-7341.2020v3n1p222

tradicionales que se forman por el afecto entre individuos que tienen sus propias características en su organización ocupando y utilizando los territorios y recursos naturales con condición de desarrollo cultural, social y religioso. Por lo tanto, el trabajo busca abordar cómo la violencia cultural afecta la sociabilidad entre las comunidades tradicionales y la sociedad a través de una revisión bibliográfica de la sociabilidad, las comunidades tradicionales y la violencia cultural.

PALABRAS CLAVE: Sociabilidad. Cultura Violencia cultural.

Recebido em: 01.10.2019. Aceito em: 09.10.2019. Publicado em: 01.01.2020. 


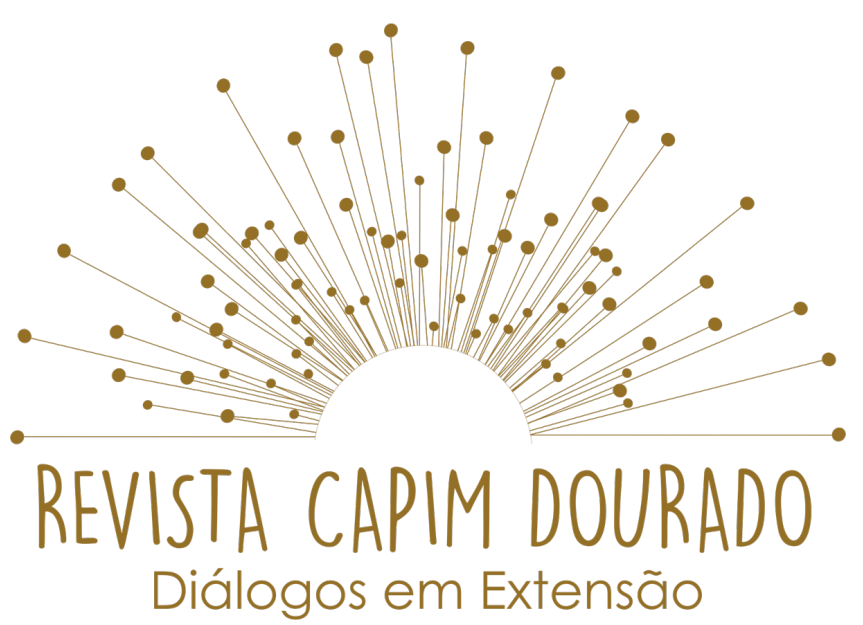

ISSN n² 2595-7341

Vol. 3, n. 1, Janeiro-Abril, 2020

DOI: http://dx.doi.org/10.20873/uft.2595-7341.2020v3n1p222

\section{Introdução}

Pesquisas demonstram que a convivência do homem em comunidades rurais e tribos passaram por grandes mudanças na vida a partir da sociabilidade com a sociedade formada por leis, regulamentos, e contratos arbitrários (BRANCALEONE, 2008; COSTA, 2010), como as escolas, os bairros, as instituições e as nações. Diante disso, essa relação trouxe a determinação de fatos sociais e de suas restrições, de acordo com a perspectiva positivista funcionalista discutida por Emile Durkheim (ARAÚJO, BRIDI, MOTIM, 2013). Sendo assim, dentro da sociedade os grupos dominantes são mais fortalecidos, tem melhor representação na defesa de suas preferências, dando a todos de forma individual o cumprimento das ordenações estabelecidas (ARAÚJO; BRIDI e MOTIM, 2013).

A fundamentação teórica traz contribuições significativas para a sustentação de planejamentos locais de desenvolvimento sustentável que estude a delimitação de seus territórios, preservando a identidade e a cultura das comunidades tradicionais que são afetadas pela violência cultural estabelecida pela sociedade contemporânea.

O trabalho apresentado aborda de que maneira a violência cultural afeta a sociabilidade entre as comunidades tradicionais e a sociedade com o objetivo geral de analisar o impacto da violência cultural nas comunidades tradicionais diante da sociedade.

Para alcançar o objetivo principal desta pesquisa, foram propostos os seguintes objetivos específicos: compreender as comunidades tradicionais, compreender a violência cultural estabelecidas pela sociedade e descrever como 


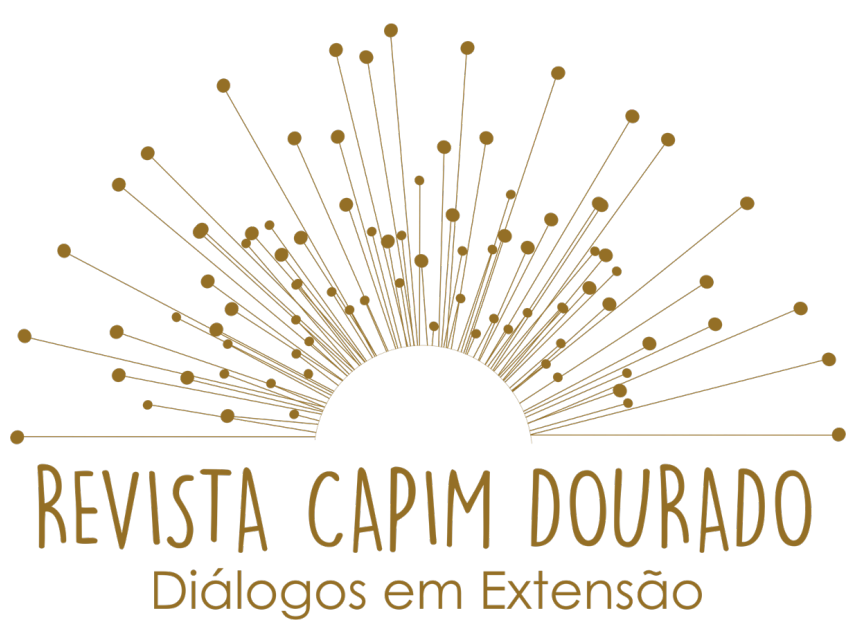

ISSN n² 2595-7341

Vol. 3, n. 1, Janeiro-Abril, 2020

DOI: http://dx.doi.org/10.20873/uft.2595-7341.2020v3n1p222

a sociabilidade das comunidades tradicionais é afetada pela sociedade contemporânea.

A pesquisa tem uma abordagem qualitativa e caráter exploratório, para se alcançar o objeto foi realizado um levantamento bibliográfico sobre os seguintes temas: sociabilidade, comunidades tradicionais e violência cultural. Para tanto, foi utilizada a plataforma Scopus e portal de periódicos da Capes para a pesquisa de artigos que abordam a sociabilidade, comunidades tradicionais e violência cultural, além da exploração bibliográfica.

\section{Resultados e discussões}

\section{Sociabilidade}

A partir da perspectiva crítica estabelecida pela escola de Frankfurt nos anos 1930 debate- se a racionalização comunicativa do homem. De acordo com Jürgen Habermas, pensador contemporâneo que defende a filosofia da teoria crítica, a sociabilidade estabelece elementos conceituais das relações sociais na atual sociedade.

A comunicação efetiva é uma fonte de pressupostos pré racionais (Habermas, 1987, p. 235; Habermas, 1996, p. 22), um fundamento de qualquer enunciado, ato de fala. Esses pressupostos se somam ao conhecimento cultural intersubjetivo que sustenta o processo de comunicação, mas, como tal, não pode ser expresso em julgamentos verbalizados. Ainda assim, embora o conhecimento cultural precognitivo seja indispensável para a comunicação efetiva, não é o único fator significativo na ação comunicativa. 


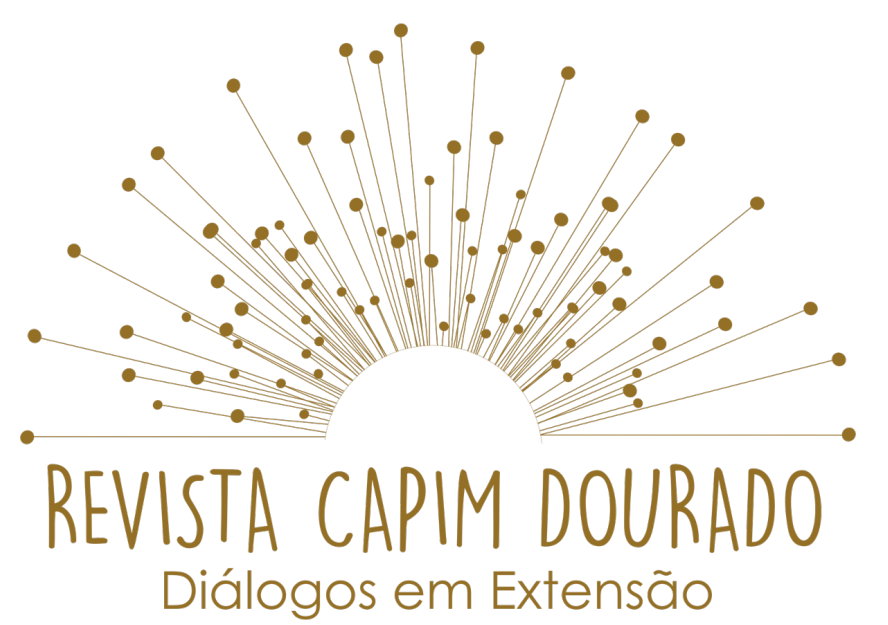

ISSN n² 2595-7341

Vol. 3, n. 1, Janeiro-Abril, 2020

\section{DOI: http://dx.doi.org/10.20873/uft.2595-7341.2020v3n1p222}

As relações, dependências e interações são explicadas por Habermas no exemplo da evolução social, onde ele vê a evolução social como um processo de diferenciação que se desenvolve em dois níveis, um com a diferenciação que envolve um aumento na racionalidade e outro que envolve a complexidade do sistema (Habermas, 1987, p. 268). Como consequência, as possibilidades de alcançar um consenso e integração social se multiplicam a medida que os indivíduos podem exibir sistemas de conhecimento de fatos, normas e sentimentos.

A mídia fundamental que orienta os sistemas sociais compreende a economia e a administração (Habermas, 1987, p. 297). Eles permitem que os sistemas sociais complexos, os estados, sofram e se desenvolvam enquanto o mundo da vida cresce cada vez mais vulnerável à objetivação, ao isolamento e à colonização.

Os participantes na ação comunicativa podem assim fazer reivindicações de validade em relação a qualquer um desses mundos e depois negociá-los. As reivindicações de validade refletem necessidades pessoais, aspirações e objetivos que devem ser confrontados com necessidades, aspirações e objetivos de outros indivíduos, bem como com sistemas sociais. Para chegar a um entendimento, todos os participantes na interação devem estar adequadamente preparados para a formulação de reivindicações de validade.

Ao rejeitar um ato de discurso como errado ou falso ou insincero, ele, o interlocutor está expressando com o "não", fato de que o enunciado não cumpriu sua função de assegurar uma relação interpessoal, de representar estados de 


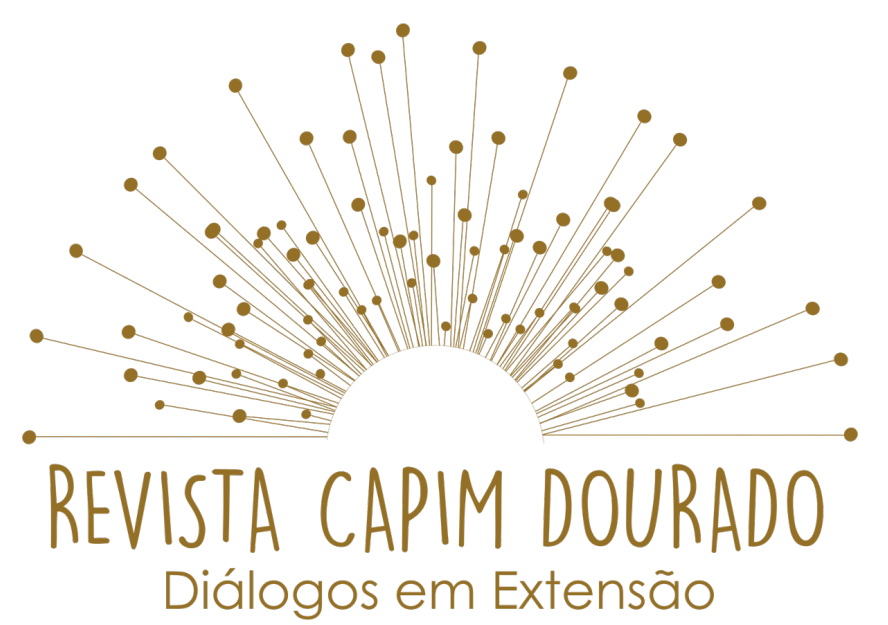

ISSN n² 2595-7341

Vol. 3, n. 1, Janeiro-Abril, 2020

DOI: http://dx.doi.org/10.20873/uft.2595-7341.2020v3n1p222

coisas ou de experiências de manifestação. Não está de acordo com o nosso mundo de relações interpessoais legitimamente ordenadas, ou com o mundo dos estados de coisas existentes, ou com o próprio mundo das experiências subjetivas do falante (Habermas, 1984, p. 308).

\section{Comunidades Tradicionais}

Ferdinand Tönnies (apud BRANCALEONE, 2008) destaca como evoluiu e desenvolveram-se os grupamentos humanos guiados pelas relações sociais estabelecidas diante das vontades naturais, exatamente ligadas à afetividade, que nas comunidades se constituem nas relações sociais diretas ausentando de tecnologias e meios de comunicação, possuindo uma quantidade limitada de indivíduos que tem clareza nos limites de sua comunidade dentro de seu território.

Neste sentido, Brandão (2010) esclarece que as inúmeras comunidades tradicionais são grupos humanos que abrangem territórios, socializam exclusivamente com a natureza, convive-se com outras comunidades tradicionais, por fim, satisfaçam-se sem a necessidade, mantendo-se fora da sociedade artificial principalmente na cidade.

$\mathrm{Na}$ comunidade tradicional se sobrelevam os hábitos e os costumes coadunados às tradições e afetividade, ao mesmo tempo em que na sociedade prevalecem as relações racionais e burocráticas fixas aos padrões formais, documentais e legais. (MORAES, 2017; BRANCALEONE, 2008; TÖNNIES, 1957). 


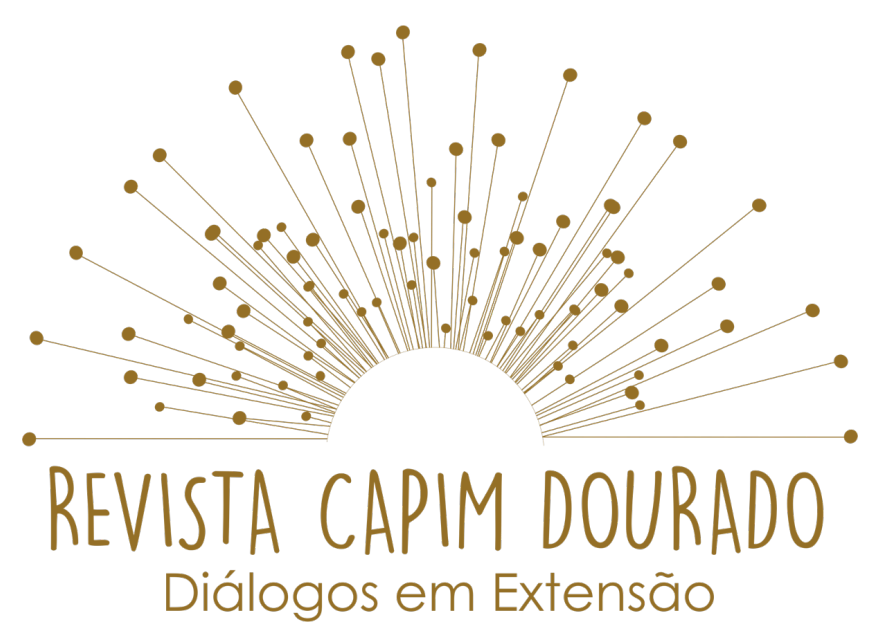

ISSN n² 2595-7341

Vol. 3, n. 1, Janeiro-Abril, 2020

DOI: http://dx.doi.org/10.20873/uft.2595-7341.2020v3n1p222

De acordo com Moraes (2005) e Hall e Ykemberry (1990) é essencial relevar que 0 componente religioso aparece bastante presente em qualquer apresentação sobre o inicio do Estado. Os povos sumérios são apresentados pela literatura associada a antropologia, como o primeiro povo da região mesopotâmica a criar a agricultura e a irrigação. Os indivíduos da comunidade amavam os deuses que eram ligados à natureza e aos sentimentos.

Neste sentido, o senso comum estimula a uma crença que nos contextos sociais as comunidades tradicionais em geral se opõem à sociedade contemporânea, marcada pelo modo de produção capitalista e sobre a notabilidade do grupo para a gestão do grupo. Contudo, as comunidades tradicionais não se opõem a sociedade contemporânea e urbana, mas destinamse conservação de seus valores de seus costumes e de suas crenças e por ampliação de sua identidade territorial e humana (MORAES et al., 2017).

\section{Violência cultural}

Ao definir a violência cultural, Galtung (1969) observa que a violência está presente quando os seres humanos estão sendo influenciados para que suas realidades somáticas e mentais sejam inferiores às suas realizações potenciais, enquanto a violência somática exemplifica a violência física, a violência mental atua nos níveis psicológicos e culturais. Para Galtung, a violência ocorre quando a distância entre o potencial e o real aumenta, então a violência ocorre quando a saúde física e o bem-estar corporal são impedidos ou quando o bem-estar psicológico, emocional e cultural de alguém é dificultado. 


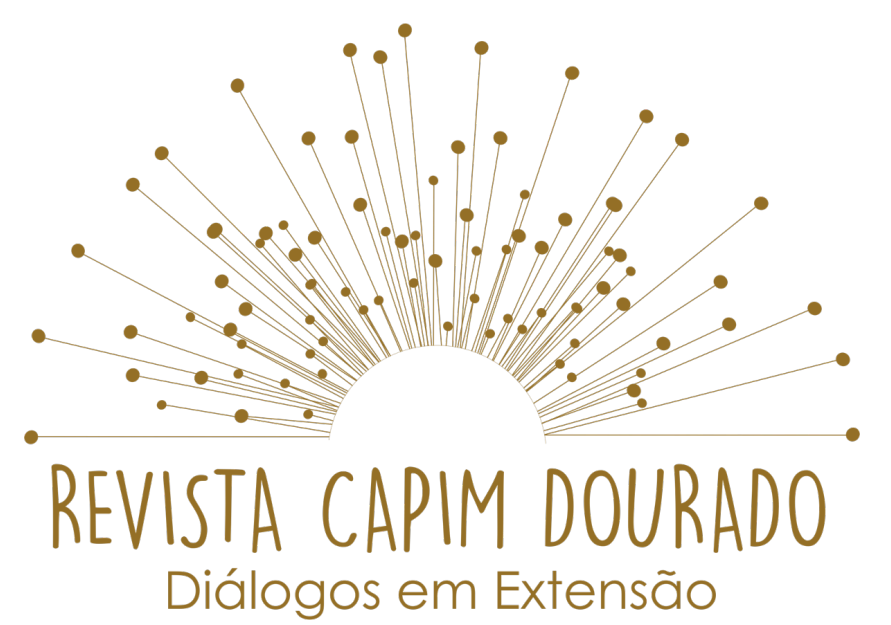

ISSN n² 2595-7341

Vol. 3, n. 1, Janeiro-Abril, 2020

DOI: http://dx.doi.org/10.20873/uft.2595-7341.2020v3n1p222

Galtung (1990, p. 291) aborda a violência cultural como qualquer aspecto de uma cultura que possa ser usada para legitimar a violência em sua forma direta ou estrutural. A violência cultural opera na esfera simbólica da existência humana exemplificada pela religião, ideologia, arte, etc. A violência cultural é um processo psicológico derivado de mentiras, doutrinação e lavagem cerebral e o mecanismo de internalização desse processo.

Como argumenta Galtung (1990), a violência cultural destaca formas pelas quais a violência direta e a violência estrutural é legitimada e tornam-se aceitáveis na sociedade. A violência direta é muitas vezes um evento, a violência estrutural, um processo, a violência cultural é a permanência e, devido à lenta transformaçã

Cabral, R., Gothardo, J. e Murback, L. (2015) relatam em seus estudos que são vários os desafios para o estabelecimento da cultura de paz, mas torna-se necessário que essa cultura seja implementada nas comunidades com mais efetividade para uma transformação social e mudanças comportamentais da sociedade e comunidades havendo uma sociabilidade maior e de respeito entre ambos.

As comunidades nas cidades se relacionam ao atendimento das dificuldades das pessoas que habitam nesse meio urbano (BRANDÃO, 2010, p. 347). Contudo, as comunidades tradicionais não se opõem a sociedade contemporânea e urbana, mas destinam-se na conservação de seus valores de seus costumes e de suas crenças, por ampliação de sua identidade territorial e humana (MORAES et al., 2017). 


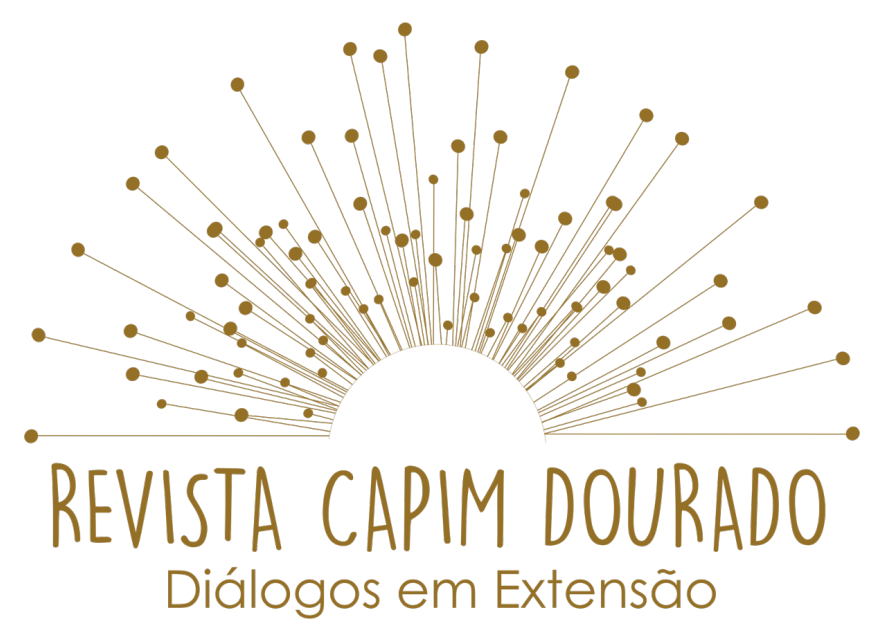

ISSN n² 2595-7341

Vol. 3, n. 1, Janeiro-Abril, 2020

DOI: http://dx.doi.org/10.20873/uft.2595-7341.2020v3n1p222

A violência cultural é aquela que traduz, ou justifica os comportamentos que legitimam socialmente a violência pessoal (onde as vítimas são visíveis) e a violência estrutural (que é o resultante da desigualdade de poder e da justiça social). Com a violência cultural há mudanças nas práticas culturais e nas crenças das comunidades, tornando-as mais vulneráveis e suscetíveis às mudanças impostas pela sociedade.

A cultura de paz procura desconstruir a violência cultural, pois ela promove diálogos, e nivelamentos entre as comunidades envolvendo o Estado, o terceiro setor e as organizações, no mundo capitalista (CABRAL, R.; GOTHARDO, J.; MURBACK, L., 2015).

\section{Considerações finais}

As marcas culturais ou tradicionais e religiosas são determinantes para 0 entendimento das comunidades tradicionais, pois de acordo com esses valores imateriais as convivências e vínculos da vida social se consolidam formando agrupamentos de indivíduos.

As organizações, inclusivamente hierárquicas, mesmo tribais, não tendo a presença do Estado, se constituem passando a ser intensamente respeitada e finalmente superam à materialidade das coisas, como a pinturas de corpos, caracterização do artesanato, das vestimentas, da culinária, da agricultura e do dialeto ou língua criada pelo grupo, que mantendo a sociabilidade com a sociedade muda sua maneira de viver. 


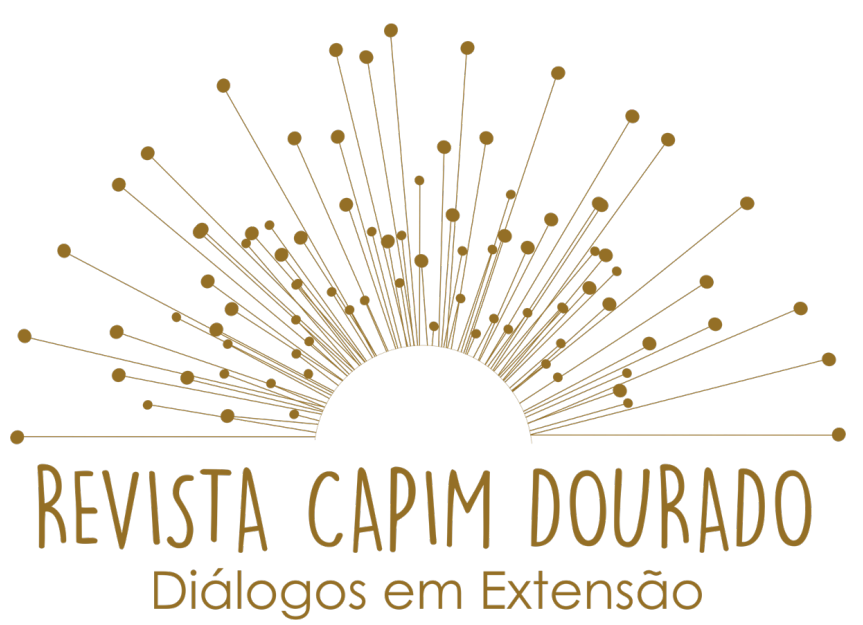

ISSN n² 2595-7341

Vol. 3, n. 1, Janeiro-Abril, 2020

DOI: http://dx.doi.org/10.20873/uft.2595-7341.2020v3n1p222

A partir do momento que a sociedade não respeita, não valoriza e interage com essas comunidades tradicionais, a violência cultural é incitada, promovendo a perda cultural dos princípios provindos das comunidades tradicionais que se formaram a partir da afetividade entre os indivíduos que possuem identidades próprias de organização social, que ocupam e utilizam territórios e recursos naturais como condição para seu desenvolvimento cultural, social e religioso, utilizando conhecimentos e práticas geradas e transmitidas por tradição.

\section{Referências}

ARAÚJO, S.M.; BRIDI, Maria Aparecida; MOTIM, Benilde Lenzi. Sociologia: um olhar crítico. São Paulo: Contexto, 2013.

ALVES, E. J.; SILVA, B. D. DA; SILVA, R. DA S. DA. MAPEAMENTO DOS ESTUDOS SOBRE A FORMAÇÃO DE PROFESSORES NO ÂMBITO DO PROCESSO DE BOLONHA EM PORTUGAL. Revista Observatório, v. 3, n. 6, p. 248-273, 1 out. 2017.

BRAGA, W. R. DE O.; MORAES, N. R. DE; DIAS BAPTISTA, R.; PUTTI, F. F.; BRAGA JÚNIOR, S. S. A CONSTRUÇÃO DA PERCEPÇÃO AMBIENTAL DE ESTUDANTES UNIVERSITÁRIOS BRASILEIROS. Revista Observatório, v. 4, n. 3, p. 1076-1106, 29 abr. 2018.

BERNARDO, C. H. C.; BRAGA JÚNIOR, S. S.; MARQUES, M. D.; GOMES, S. C. V.; QUEIROZ, T. R. Percepção dos produtores rurais de Tupã, SP, sobre o processo de comunicação para execução da logística reversa de embalagens de agrotóxicos. Revista Observatório , v. 1, n. 3, p. 242-270, 26 dez. 2015.

BUENO, T. C.; REINO, L. S. A. ENTRE A TABLOIDIZAÇÃO E O TEASER PUBLICITÁRIO: uma análise dos títulos caça-cliques. Revista Observatório , v. 4, n. 3, p. 675-707, 29 abr. 2018.

BRANCALEONE, C. Comunidade, sociedade e sociabilidade: revisitando Ferdinand Tönnies. Revista de Ciências Sociais. v. 39, n.1, 2008. 


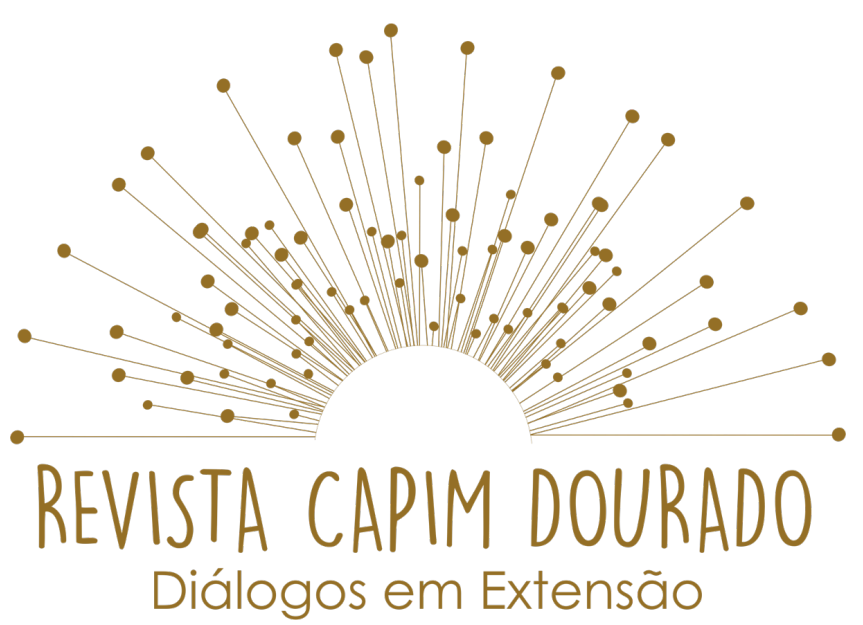

ISSN n² 2595-7341

Vol. 3, n. 1, Janeiro-Abril, 2020

DOI: http://dx.doi.org/10.20873/uft.2595-7341.2020v3n1p222

BRANDÃO, C.R. A comunidade tradicional. In: COSTA, João Batista Almeida. LUZ, Cláudia (Orgs.). Cerrado, Gerais, Sertão: comunidades tradicionais dos sertões roseanos. Montes Claros: (n prelo). p. 1-365, 2010.

BRAGA, W. R. DE O.; MORAES, N. R. DE; DIAS BAPTISTA, R.; PUTTI, F. F.; BRAGA JÚNIOR, S. S. A construção da percepção ambiental de estudantes universitários brasileiros. Revista Observatório , v. 4, n. 3, p. 1076-1106, 29 abr. 2018.

CABRAL, R.; GOTHARDO, J.; MURBACK, L. A cultura de Paz no contexto das relações públicas comunitárias e responsabilidade social. Revista Razón y Palabra, Monterrey, n. 88, p. 21, fev. 2015.

COSTA, C. Sociologia: introdução à ciência da sociedade. São Paulo: Moderna, 2010.

ELHAJJI, M.; ESCUDERO, C. WEBDIÁSPORA: Migrações, TICS e memória coletiva. Revista Observatório, v. 2, n. 5, p. 334-363, 25 dez. 2016.

EVANGELISTA, F.; MARTINS, K. D.; ANGELINI, M. F. C.; ROCHA, M. J. F. SOCIEDADE DO CONHECIMENTO: O uso das TIC por docentes e as novas articulações de saberes educacionais no sudeste do Pará. Revista Observatório , v. 5, n. 5, p. 188208, 1 ago. 2019.

DE MORAES, N. R.; BRUMATTI, L. M.; LIMA, A. R.; CAMPOS, A. C. ANÁLISE DA CONVERGÊNCIA CONCEITUAL DOS TERMOS "TERRITÓRIO" E "COMUNIDADE TRADICIONAL" NO BRASIL. Revista Observatório, v. 3, n. 4, p. 518-539, 1 jul. 2017. DE MORAES, N. R.; CAMPOS, A. C.; SILVA, M. L.; SOUZA, F. C. COMUNIDADES TRADICIONAIS: cultura e identidade. Revista Observatório, v. 3, n. 5, p. 501-522, 1 ago. 2017.

DE MORAES, N. R.; MARTÍNEZ, M. P.; RUIZ, S. C. M.; MOMBELLI, G. S.; BISPO, B. L.; SILVA, G. T. B. E; PACANARO, Y. G. Origens teóricas da corrupção na gestão pública contemporânea: debate conceitual. Revista Observatório, v. 1, n. 2, p. 156-173, 8 dez. 2015.

FANON, F. The wretched of the earth. London, England: Penguin, 1967.

GALTUNG, J. Cultural violence. Journal of Peace Research, v. 27, n. 3, p. 291-305, 1990. 


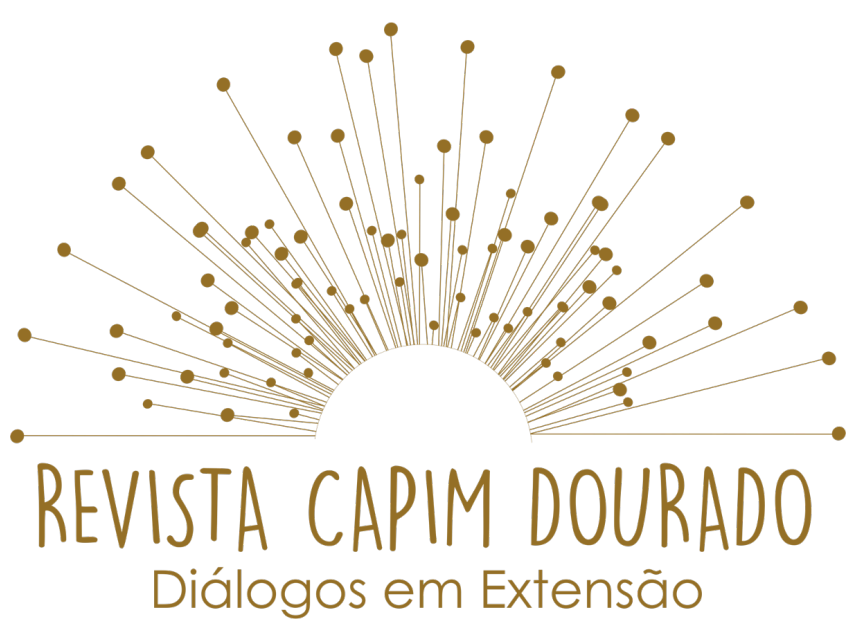

ISSN n² 2595-7341

Vol. 3, n. 1, Janeiro-Abril, 2020

DOI: http://dx.doi.org/10.20873/uft.2595-7341.2020v3n1p222

GALTUNG, J. Violence, peace, and peace research. Journal of Peace Research, v. 6, n. 3, p. 167-191, 1969.

HABERMAS, J. Between facts and norms: Contributions to a discoursetheory of law and democracy. Cambridge, MA: The MIT Press, 1996.

HABERMAS, J. The theory of communicative action, volume 1. Reason and the rationalization of society. Boston: Beacon Press, 1984.

HABERMAS, J. The theory of communicative action, volume 2. Lifeworldand system: A critique of functionalist reason. Boston: Beacon Press, 1987.

HALL, J.A.; YKEMBERRY, G.J. O Estado. Lisboa/Portugal: Estampa, 1990.

LOPES, P.; PEREIRA, S.; MOURA, P.; CARVALHO, A. Avaliação de competências de literacia mediática: o caso português. Revista Observatório , v. 1, n. 2, p. 42-61, 8 dez. 2015.

MARTINEZ, M. Reflexões sobre Jornalismo e História Oral: um campo com mais convergências do que dissonâncias. Revista Observatório , v. 2, n. 1, p. 75-91, 1 maio 2016.

MOIO, I.; ALCOFORADO, L.; VIEIRA, C. C. A DECLARAÇÃO DE BOLONHA E O REFORÇO DA ABERTURA DO ENSINO SUPERIOR A NOVOS PÚBLICOS: perceções de pessoas adultas que frequentam a Universidade de Coimbra. Revista Observatório , v. 3, n. 6, p. 169-201, 1 out. 2017.

MORAES, N. R. DE; CAMPOS, A. DE C.; MÜLLER, N. DE M.; GAMBA, F. B.; GAMBA, M. F. D. D. F.; BRAGA, W. R. DE O. O CONCEITO DE TERRITÓRIO DENTRO DE COMUNIDADES TRADICIONAIS BRASILEIRAS. Revista Observatório, v. 2, n. 4, p. 442-455, 30 out. 2016.

MORAES, N. R. DE; SOUZA, F. DA C.; MARCHETTI, C. T. B.; MORAES , F. G. DE; FONSECA, J. J. INTERDISCIPLINARIDADE, CRITICIDADE E FORMAÇÃO SOCIOAMBIENTAL NA UNIVERSIDADE . Revista Observatório, v. 5, n. 5, p. 890905, 1 ago. 2019.

MORAES, N.R. As empresas e o atendimento às demandas sociais em Bauru/SP: responsabilidade ou marketing? Franca/SP, 2005. 140f. Dissertação (Mestrado em Serviço Social). Faculdade de História, Direito e Serviço Social, UNESP. 


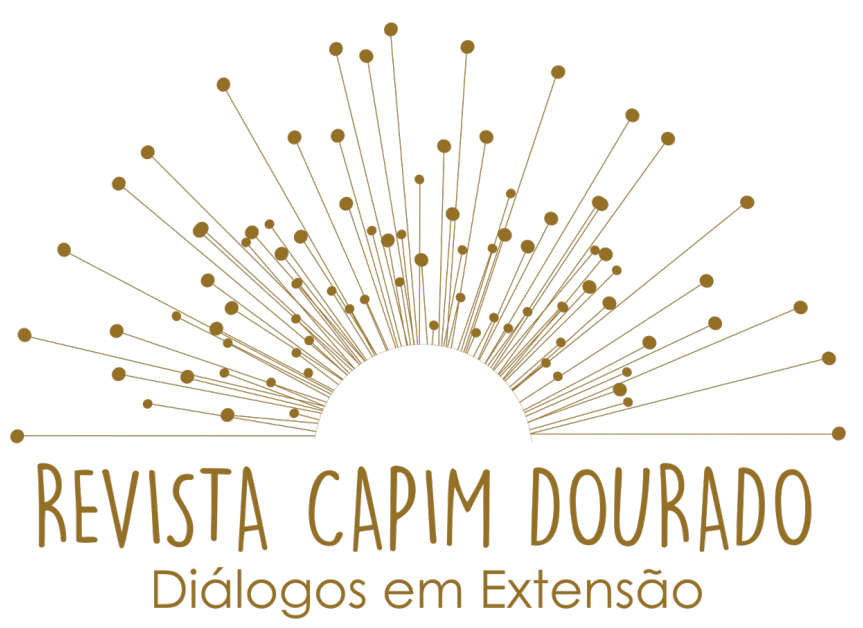

ISSN n² 2595-7341

Vol. 3, n. 1, Janeiro-Abril, 2020

DOI: http://dx.doi.org/10.20873/uft.2595-7341.2020v3n1p222

MORAES, N.R.; CAMPOS, A.C.; MÜLLER, N.M.; GAMBA, F.B; GAMBA, M.F.D.D.F. As comunidades tradicionais e a discussão sobre o conceito de território. Revista Espacios. v. 38, n. 12, 2017, p.17.

NUNES, S. G.; PORTO JUNIOR, F. G. R.; MORAES, N. R. DE. CONHECIMENTO E ORGANIZAÇÃO: indicativos pós-Bolonha de uma sociedade em construção. Revista Observatório, v. 3, n. 6, p. 338-353, 1 out. 2017.

PORTO JUNIOR, F. G. R.; MORAES, N. R. DE. FORMANDO PESQUISADORES PÓSBOLONHA EM PORTUGAL: relações entre a formação de graduação e o campo da pesquisa/investigação. Revista Observatório, v. 3, n. 6, p. 202-228, 1 out. 2017. REINO, L. S. A.; PELLANDA, E. C. JORNALISMO BASEADO EM LOCALIZAÇÃO: O caso do Breaking News. Revista Observatório , v. 3, n. 3, p. 229-260, 1 maio 2017. SANTOS, E.; MARTINS, V. CIBERVÍDEOS E MULTILETRAMENTOS NA EDUCAÇAO ONLINE. Revista Observatório , v. 4, n. 5, p. 231-262, 1 ago. 2018.

SOUZA, F. DA C.; MORAES, N. R. DE. ESTADO DE BEM-ESTAR SOCIAL: UMA SILVA, B. D. DA; ALVES, E. J.; PEREIRA, I. C. A. DO QUADRO NEGRO AO TABLET: Desafios da docência na era digital. Revista Observatório, v. 3, n. 3, p. 532-560, 1 maio 2017.

TEIXEIRA, I.; DA SILVA, V. C.; MARTINS, J. L. A CONVERGÊNCIA MIDIÁTICA E AS TECNOLOGIAS MÓVEIS PÓS-BOLONHA: NOVAS PRÁTICAS SOCIAIS. Revista Observatório , v. 3, n. 6, p. 229-247, 1 out. 2017.

TREVISAN, M. K.; DE PRÁ, E. B.; GOETHEL, M. F. Meme: intertextualidades e apropriações na Internet. Revista Observatório , v. 2, n. 1, p. 277-298, 1 maio 2016. TÖNNIES, F. Community and Society. Trad. Charles P. Loomis. EUA: Michigan State University Press, 1957.

VIANA, J.; COSTA, F. A.; PERALTA, H. APRENDIZAGENS PESSOAIS EM CONTEXTOS INFORMAIS: oportunidades criadas pela Internet. Revista Observatório , v. 3, n. 4, p. 190-231, 1 jul. 2017. 